\title{
Novel flow cytometry technique for detection of Plasmodium falciparum specific B-cells in humans: increased levels of specific B-cells in ongoing infection
}

\author{
Allan Lugaajju ${ }^{1,3}$, Sreenivasulu B. Reddy ${ }^{3}$, Caroline Rönnberg ${ }^{3}$, Mats Wahlgren ${ }^{3}$, Fred Kironde ${ }^{1,2}$ \\ and Kristina E. M. Persson $3,4^{*}$
}

\begin{abstract}
Background: Malaria caused by Plasmodium falciparum is still a major health threat in endemic areas especially for children below 5 years of age. While it is recognized that antibody immunity plays an important role in controlling the disease, knowledge of the mechanisms of sustenance and natural boosting of immunity is very limited. Before, it has not been possible to investigate malaria specific B-cells directly in flow cytometry, making it difficult to know how much of a B cell response is due to malaria, or how much is due to other immunological stimulators.

Methods: This study developed a technique using quantum dots and schizont extract made from ghosts of infected erythrocytes, to be able to investigate P. falciparum specific B-cells, something that has never been done before.

Results: Major differences in P. falciparum specific B-cells were found between samples from immune (22.3\%) and non-immune (1.7\%) individuals. Samples from parasite positive individuals had the highest proportions of specific B-cells (27.9\%).

Conclusion: The study showed increased levels of P. falciparum-specific B-cells in immune individuals, with the highest levels in active malaria infections, using a new technique that opens up new possibilities to study how these cells are sustained in vivo after natural infections. It will also be useful in vaccine studies.
\end{abstract}

Keywords: Plasmodium falciparum, Quantum dots, Ghost infected red blood cells, Malaria, B-cells

\section{Background}

Clinical immunity to Plasmodium falciparum malaria is acquired and maintained by repeated exposure to the parasite [1]. Classical studies have demonstrated that passively transferred IgG from semi-immune adults with repeated prior exposure to $P$. falciparum infection can clear or reduce parasitaemia in individuals acutely infected with P. falciparum [2]. However, the mechanisms by which antibody-secreting cells are induced and maintained for long-term disease protection are poorly understood. In order to appreciate how P. falciparum specific

\footnotetext{
*Correspondence: kristina.persson@med.lu.se

${ }^{4}$ Department of Laboratory Medicine, Lund University, Lund, Sweden Full list of author information is available at the end of the article
}

B-cells are induced and maintained in vivo, these cells need to be separated from other B-cells. The maintenance of serum antibody levels after exposure to antigen either by infection or immunization has been referred to as serological memory [3]. There is long-standing evidence that naturally acquired immunity to the erythrocytic stages of malaria is strongly dependent on antibodies [48]. Memory B-cells play an important role in memory for different pathogens, by boosting the immune response in times of secondary exposure. Naturally the kinetics of antibodies is a balance between production and decay. Studies have shown that production of antibodies against merozoite antigens is not sustained following an acute episode of malaria $[4,9]$. Antibody production can be sustained through restimulation of memory B-cells 
by persistent antigens [10] or by non-proliferating long lived plasma cells [11]. The mechanisms mediating the development of short-lived antibody secreting cells and long lived plasma cells are not well understood. However, it appears that short-term serological memory may be dependent on antigen stimulation whereas long-term serological memory is antigen independent and depends on homeostatic activation. Studies have shown that during acute malaria infection, there are acute alterations in memory B-cell numbers [12]. However, these studies used the entire B-cell population without differentiating whether they were $P$. falciparum specific or not.

Controversy still prevails as to why memory in human malaria infections is short-lived [13]. Antibody levels to some malarial antigens, although not all, have been found to rapidly decline after the end of the transmission season and it has been shown that immunity is short-lived in the absence of reinfection [14-19]. This implies that B-cell memory to malaria may be defective or suboptimal. Weiss et al. [20] provided evidence that an atypical memory B-cell population is significantly expanded in $P$. falciparum-exposed Malian adults and children as young as 2 years of age. While atypical and classical memory B-cells appear closely related developmentally, atypical memory B-cells exhibit markedly reduced signaling and effector functions, which may contribute to the inefficient acquisition of humoral immunity to malaria [21].

Some studies in animal models have shown that memory B-cells do develop and are maintained normally after malaria infections [22, 23], whereas others have found that malaria infection interferes with the development of memory B-cells and long-lived plasma cells [24, 25]. In humans, several studies have demonstrated stable antibody responses to malaria antigens [26-28]. However, short-lived antibody responses have also been observed $[29,30]$, especially in young children [27]. Dorfman et al. [30] were frequently unable to detect circulating malariaspecific B-cells in seropositive children, but it is unclear whether this reflects an absence of such cells or a lack of sensitivity in the assays used to detect them. Nahrendorf et al. [31] showed gradual acquisition of memory B-cells and antibodies recognizing pre-erythrocytic and crossstage antigens after $P$. falciparum sporozoite immunization. However, the magnitude of these humoral responses did not correlate with protection but directly reflected parasite exposure in chemoprophylaxis and sporozoites immunization and challenge. Asito et al. [12] observed an increase in both the total memory B-cell population and the transitional B-cell population, following an episode of acute malaria in African children. However, this study lacked any analysis of the specificity of B-cell responses as well as long-term follow up to ascertain the duration of the response. One study showed that even if antigen-specific antibodies were not detected in plasma, antigen-specific B-cells could still be found circulating in the blood, suggesting that these could be maintained independently of long-lived plasma cells [32]. Most of these studies used Elispot assays for the detection of antigen specific memory B-cells. It has been suggested before that flow cytometry is a good method for estimation of antigen-specific cells [33] in situations with complex antigens, compared to ELISA-based assays, and malaria is certainly a case where there are several setups of antigens, containing a range of merozoite, sporozoite and infected erythrocyte antigens where the concentration of each specific B-cell is often very low. Even though ELISAbased assays can be made more sensitive through different measures, it is still estimated that they might detect only $70 \%$ of the response found when using flow cytometry [33]. An advantage of using direct flow cytometry, as in the method described here, is that no stimulation of the cells is needed, increasing the chances of including all cells in the reading. When this method was used in a set of immune and non-immune donors, very clear differences were found between the two groups, with the highest levels in on-going malaria infection.

\section{Methods}

\section{Sample collection and processing}

Samples from malaria endemic $(\mathrm{n}=57)$ and nonendemic areas $(n=25)$ were collected from Kasangati Health Centre, Uganda, and Karolinska University Hospital (blood donors), respectively. All samples from Kasangati, except seven of the RDT positive samples, were collected during the high transmission season. Additionally, five samples with an inflammatory condition other than malaria were collected during the low transmission season. 10 Samples each from Ugandan and Swedish donors were also collected for protocol standardization. Written informed consent was obtained from all study participants in Uganda and the study protocol was approved by the appropriate Ethical review committee (Uganda: 2011-114, Sweden: 2014-478-32). Blood (5-10 $\mathrm{mL})$ was drawn in lithium heparinized tubes (BD, Plymouth, UK) and transported to the laboratory for processing within $4 \mathrm{~h}$ after collection. Peripheral blood mononuclear cells (PBMC) were separated by Ficollhypaque (GE HealthCare Bio-Sciences AB, Sweden) density gradient centrifugation. The sample blood was diluted with equal volumes of Dulbecco's phosphate buffered saline (DPBS, Life technologies, Stockholm, Sweden), carefully layered over the Ficoll, and centrifuged for $30 \mathrm{~min}$ at $400 \mathrm{~g}$ (room temperature) with no brakes. After centrifugation, whole blood was separated into four layers, with plasma at the top followed by white blood cells containing PBMCs, a Ficoll medium layer, and a 
bottom layer containing erythrocytes and granulocytes. After the removal of the plasma, the PBMCs were carefully collected, and washed twice with DPBS at $400 \mathrm{~g}$ for $15 \mathrm{~min}$, then $300 \mathrm{~g}$ for $15 \mathrm{~min}$ to remove Ficoll traces and platelets. The cells were then resuspended in $1 \mathrm{~mL}$ RPMI media (Sigma, St Louis, MO, USA). The Cell count was done with the Neuberger counting chamber $(5 \mu \mathrm{L}$ of the cell suspension was added to $45 \mu \mathrm{L}$ of $0.4 \%$ trypan blue, Sigma, St Louis, MO, USA). The PBMCs were cryopreserved in liquid nitrogen at a concentration of $10^{7}$ cells/ $\mathrm{mL}$ in heat-inactivated $90 \%$ fetal bovine serum (Sigma, St Louis, MO, USA) and 10 \% DMSO (Sigma, St Louis, MO, USA) as previously described [34].

\section{Plasmodium falciparum infected red blood cells (iRBCs)} Plasmodium falciparum-infected red blood cells of the FCR3S 1.2 line were maintained in vitro at $\mathrm{pH} 7.4$ in sealable flasks using human group $\mathrm{O}+$ erythrocytes, at $3 \%$ haematocrit, in RPMI-HEPES medium supplemented with $50 \mu \mathrm{g} / \mathrm{mL}$ hypoxanthine, $25 \mathrm{mM} \mathrm{NaHCO}, 20 \mu \mathrm{g} /$ $\mathrm{mL}$ gentamicin, $5 \%$ (vol/vol) heat-inactivated pooled human sera from donors resident in Sweden, and $0.25 \%$ Albumax II (Gibco, Invitrogen, Mount Waverly, Australia) maintained in an atmosphere of $1 \% \mathrm{O}_{2}, 4 \% \mathrm{CO}_{2}$, and $95 \% \mathrm{~N}_{2}$ at $37{ }^{\circ} \mathrm{C}$, as previously described [35]. Cultures were synchronized two or three times per week by resuspending culture pellets in $5 \% \mathrm{D}$-sorbitol (Sigma, St Louis, MO, USA) in water to lyse trophozoite- and schizont-infected erythrocytes.

\section{Ghost Plasmodium falciparum infected red blood cells (GiRBCs)}

The pellet of $1 \times 10^{8}$ to $5 \times 10^{8}$ enriched trophozoite stage parasites ( $\sim 80 \%$ parasitaemia) was treated with Streptolysin O (SLO) from Sigma to obtain GiRBCs following the protocol in [36]. SLO treatment of infected erythrocytes results in the release of the erythrocyte cytosol. Parasites contained within an intact parasitophorous vacuole were sedimented by centrifugation at $10,000 \times g$ for $15 \mathrm{~s}$. The pellet (GiRBC) was then homogenized using a sonicator (Q500, Fisher Scientific), and the protein concentration was measured using a Nanodrop (ND2000, Thermoscientific).

\section{Quantum dot (Qdot) conjugation of iRBCs and GiRBCs Amino Qdot conjugation}

$35 \mu \mathrm{L}$ of $2 \mathrm{nmol}$ Qdot 565 amino Qdot (Invitrogen) was transferred into a clean dry glass vial. $3.5 \mu \mathrm{L}$

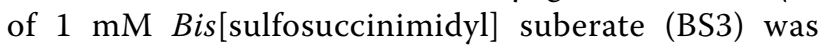
added and incubated for $30 \mathrm{~min}$ on a rotator. The Qdots were purified from excess cross-linker by buffer exchange on a clean centrifugal ultra filtration unit (Millipore Corporation), which was pre-equilibrated with $3000 \mu \mathrm{L}$ of PBS (pH 7.4). The collected eluent was added to a clean dry vial containing $225 \mu \mathrm{g}$ of iRBC/ GiRBC and mixed gently, then allowed to react for $2 \mathrm{~h}$ at room temperature on a rotator. The reaction was quenched with $1 \mathrm{M}$ glycine to a final concentration of $50 \mathrm{mM}$ for $15 \mathrm{~min}$. The conjugate solution was filtered through a $0.2 \mu \mathrm{m}$ poly ether sulfone (PES) syringe filter over a clean centrifugal ultra filtration unit (Millipore: $100 \mathrm{kDa}$ cutoff). The filtrate was washed thrice with $3 \mathrm{~mL}$ of $50 \mathrm{mM}$ borate buffer $(\mathrm{pH} 8.3)$ at $3000 \mathrm{~g}$ for $5 \mathrm{~min}$ per wash. The amino Qdot-iRBC/GiRBC conjugate solution was diluted 10 times with $10 \mathrm{mM}$ Borate buffer ( $\mathrm{pH}$ 7.4) and stored at $4{ }^{\circ} \mathrm{C}$ until further processing.

\section{Carboxyl Qdot conjugation}

$35 \mu \mathrm{L}$ of 2 nmol Qdot 565 carboxyl Qdots (Invitrogen) was transferred into a clean dry glass vial. $199 \mu \mathrm{L}$ of $10 \mathrm{mM}$ borate buffer ( $\mathrm{pH}$ 7.4) was then added. $225 \mu \mathrm{g}$ of iRBCs/GiRBC was added followed by addition of $7 \mu \mathrm{L}$ freshly prepared $10 \mathrm{mg} / \mathrm{mL} N$-ethyl- $N^{\prime}$ dimethylaminopropyl-carbodiimide (EDC). The reaction mixture was then incubated for $2 \mathrm{~h}$ at room temperature with gentle stirring. The conjugate solution was filtered, washed, and diluted as described above for Amino Qdot conjugation.

\section{Immunophenotyping of $P$. falciparum specific B-cells}

Cryopreserved PBMCs (approximately $1 \times 10^{6}$ cells) were thawed on ice and washed in cold flow buffer (PBS/0.5 \% BSA $/ 2$ mM EDTA). To each sample, $100 \mu \mathrm{L}$ flow buffer was added. To remove non-specific binding and background fluorescence, $1 \mu \mathrm{g}$ Fc block (CD16/ CD32mAb, Biolegend) was added to each PBMC sample, and incubated on ice for $5 \mathrm{~min}$. $25 \mu \mathrm{L}$ of GiRBC-Qdot conjugate was added, and incubated on ice for $30 \mathrm{~min}$. After incubation, the cells were washed and stained for CD19 B-cell phenotyping. 3.5 $\mu \mathrm{L}$ CD 19 PE CF594 fluorochrome-conjugated mouse antihuman $\mathrm{mAb}$ (BD Horizon) was used to stain $10^{6}$ cells $/ 100 \mu \mathrm{L}$ flow buffer. After staining for $30 \mathrm{~min}$, cells were washed with flow buffer and resuspended in $300 \mu \mathrm{L}$ flow buffer. Analysis was done on a LSRII flow cytometer (Becton-Dickinson Immunocytometry Systems, San Jose, USA). Data was processed using FLOWJO software (Tree Star Inc., San Carlos, CA, USA).

\section{Malaria diagnostics}

All samples from Uganda were subjected to a Combo Rapid Diagnostic Test (pLDH/HRP2, Premier Medical Corporation Limited, India) as described [37]. The parasitaemia for the malaria positive samples was calculated using microscopy according to the WHO guide lines [38]. 


\section{Results}

Comparison between amino Qdots and carboxyl Qdots

To establish the optimal volume of amino/carboxyl Qdot conjugate that reacts with the PBMC samples, the volumes of both amino and carboxyl iRBC conjugates were varied (from 10, 15, 20, 25, 30, 35, and $40 \mu \mathrm{L}$ ) on the same samples from malaria endemic and non-endemic areas. $25 \mu \mathrm{L}$ of the conjugate (containing $1 \mu \mathrm{L}$ Qdot: 6.4 $\mu \mathrm{g}$ $i R B C / G i R B C)$ was found to be optimal. Furthermore, immune and non immune immunophenotyping based on carboxyl Qdot-iRBC conjugate gave a higher P. falciparum positive frequency (even though the background was also higher), as compared to the amino Qdot-iRBCs conjugate, implying that carboxyl Qdots are better separators for $P$. falciparum specific B-cells compared to amino Qdots (Fig. 1). The mean \% of falciparum + B-cells as determined by amino and carboxyl Qdots was 0.27 and 5.38, respectively, with a $\mathrm{p}$ value of $<0.0001$. The difference between $\%$ of falciparum+ B-cells as determined by amino and carboxyl Qdots was statistically significant.

\section{Comparison of carboxyl Qdot-iRBC and carboxyl Qdot-GiRBC}

Despite carboxyl Qdot-iRBC being better separators of P. falciparum specific B-cells, they have one short-fall of unspecific binding. To reduce on the unspecific binding of carboxyl Qdot-iRBC conjugate to haemoglobin, the GiRBC (which eliminates most of the haemoglobin) was prepared and conjugated with carboxyl Qdots as described above.

Immunophenotyping experiments to compare carboxyl Qdot-iRBC with carboxyl Qdot-GiRBC on four different Ugandan blood donors showed that carboxyl QdotGiRBC gave a higher $P$. falciparum positive percentage as depicted in Fig. 2, implying that carboxyl Qdot-GiRBC is better than carboxyl Qdot-iRBC.

The mean \% of falciparum+ B-cells as determined by carboxyl Qdot-RBC and carboxyl Qdot-GiRBC was 1.2 and 4.6, respectively. The difference between $\%$ of falciparum + B-cells as determined by carboxyl Qdot-RBC and carboxyl Qdot-GiRBC was statistically significant with $\mathrm{p}$ value of $<0.0001$.

\section{Comparison of fresh and frozen PBMC}

To establish the effect of cryopreservation on PBMC using this method, two blood samples from non-immune donors were used. The PBMC were isolated from each sample using ficoll hypaque as described above. Part of the PBMC (fresh) from each sample was immediately immunophenotyped (carboxyl Qdot GiRBC and CD 19 PE CF594 fluorochrome-conjugated mouse antihuman $\mathrm{mAb}$ ) as described above. The remaining portion (frozen) was cryopreserved and immunophenotyped the same way as the fresh PBMC after 1 week. One sample showed $1.7 \%$ falciparum + B-cells when fresh and $1.6 \%$ after having been frozen, and the other sample showed $2.2 \%$ both as fresh and after freezing. Hence the freezing of PBMC has no effect on this technique.

\section{Separation of falciparum+ B-cells from falciparum- B-cells using carboxyl Qdot-GiRBC}

Immunophenotyping of $P$. falciparum specific B-cells using carboxyl Qdot-GiRBC and CD 19 PE CF594 fluorochrome-conjugated mouse antihuman $\mathrm{mAb}$ was conducted on a total of 57 samples from a malaria endemic area and 25 samples from a malaria non-endemic area. The \% of CD19+ cells that were falciparum + was higher in samples from the malaria endemic area (range 13.3$39.3 \%$, mean $22.3 \%$ ) compared to samples from the malaria non-endemic area (range $0.5-2.5 \%$, mean $1.7 \%$ ), (Fig. 3).

\section{Reproducibility}

To find out how reproducible the method is, four separate immunophenotyping experiments were conducted (using carboxyl Qdot-GiRBC, and CD 19 PE CF594 fluorochrome-conjugated mouse antihuman $\mathrm{mAb}$ ) on ten different samples from non-endemic areas using the same conditions. The mean and standard deviation per sample repeat indicated that the method is very reproducible (Fig. 4).

To further show how reproducible the method is, two separate immunophenotyping experiments were conducted on thirteen different samples, of which seven had a malaria ongoing infection, five were $P$. falciparum negative but with other inflammatory conditions, and one sample was from a non-endemic area as a control (Fig. 5). The samples from the endemic area were all collected during low transmission season. These samples were ran twice only because they had fewer cells, compared to the above non-immune samples. The mean and standard deviation for the two experiments on malaria positive samples was 26.7 (5.8), and 26.8 (5.6), $p$ value $=0.43$ indicating that the difference is not statistically significant. The mean and standard deviation for the two experiments on inflammatory samples but $P$. falciparum negative was $3.6(0.4)$, and $3.5(0.8), p$ value $=0.81$ indicating that the difference is not statistically significant and reproducibility is good, whether high or low values of falciparum + cells are measured.

\section{Comparison of falciparum + B-cells and parasitaemia}

All the 57 samples from the malaria endemic area were screened for malaria using the malaria rapid diagnostic test (RDT). Microscopy was done on the 13 samples that where RDT positive to determine the 


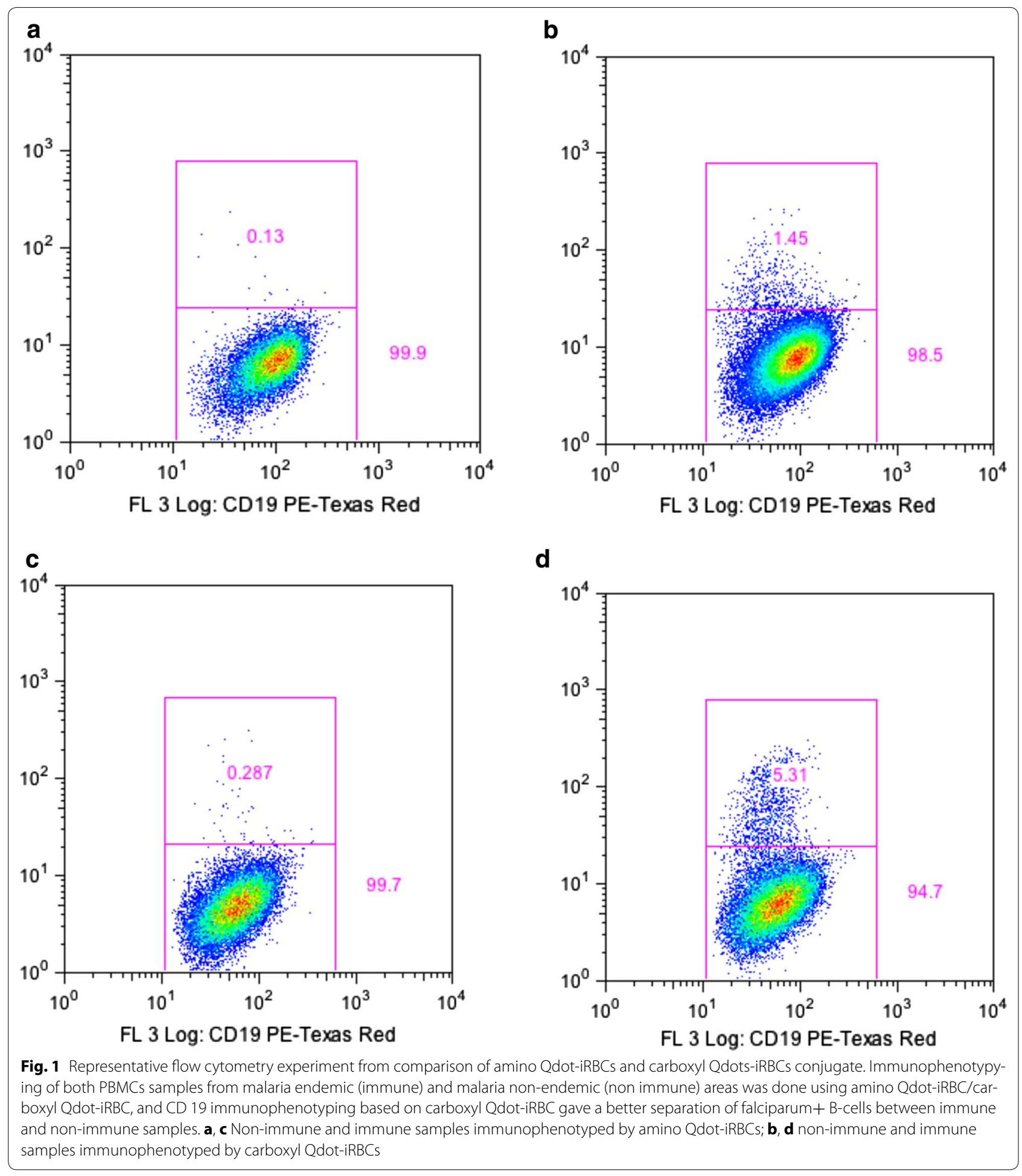

parasitaemia. The plot of \% of falciparum + B-cells and corresponding parasitaemia (Fig. 6) indicated that the higher the parasitaemia, the higher the \% of falciparum + B-cells. There was no obvious difference in results, whether the samples were collected during high or low transmission season (Fig. 6). Within the immune samples (presented in Fig. 3), the mean and standard deviation for the parasite positive $(\mathrm{n}=13)$ and parasite negative $(\mathrm{n}=44)$ samples was $27.9(6.1)$, and 20.6 (4.9), $p$ value $<0.0001$ 


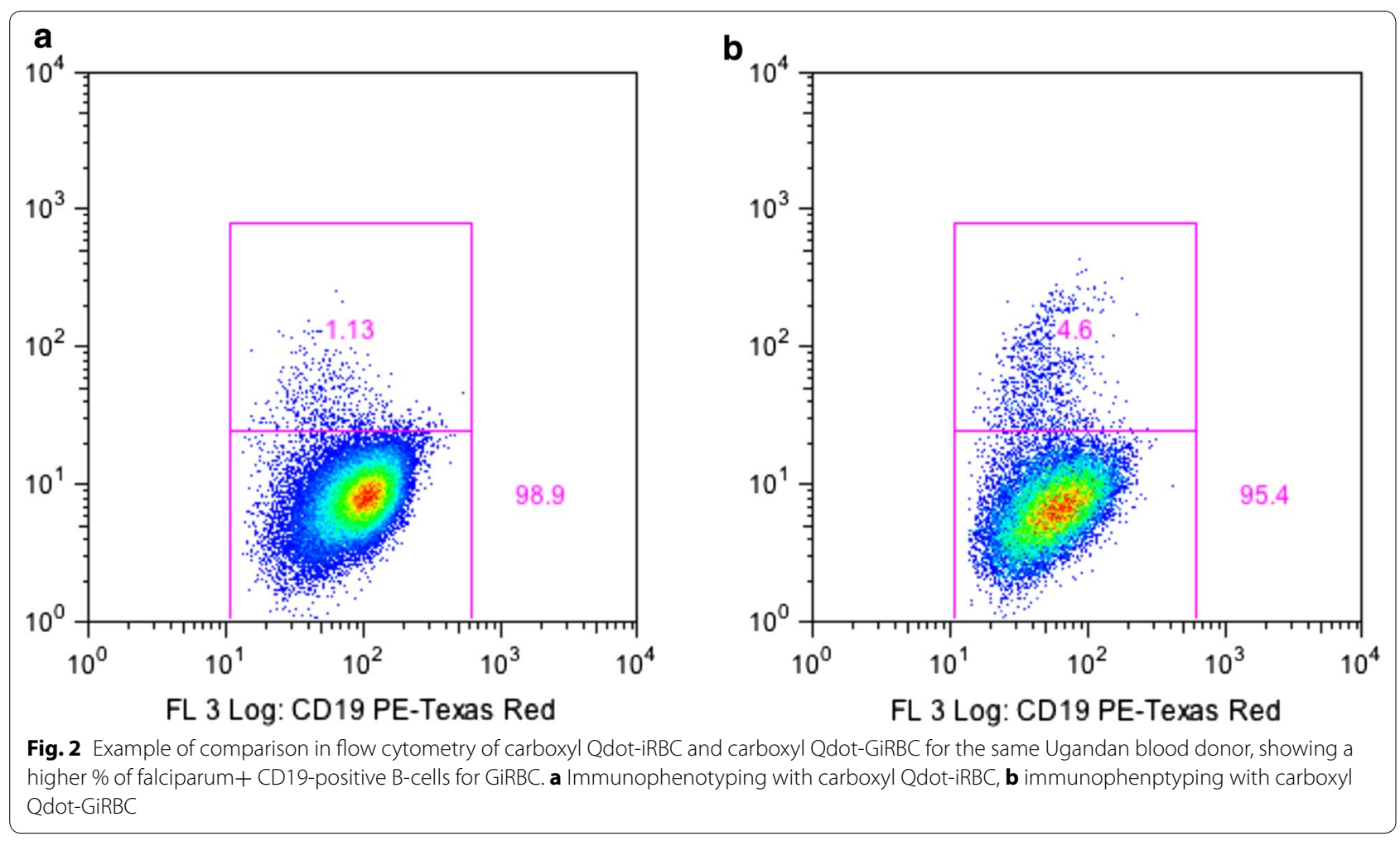

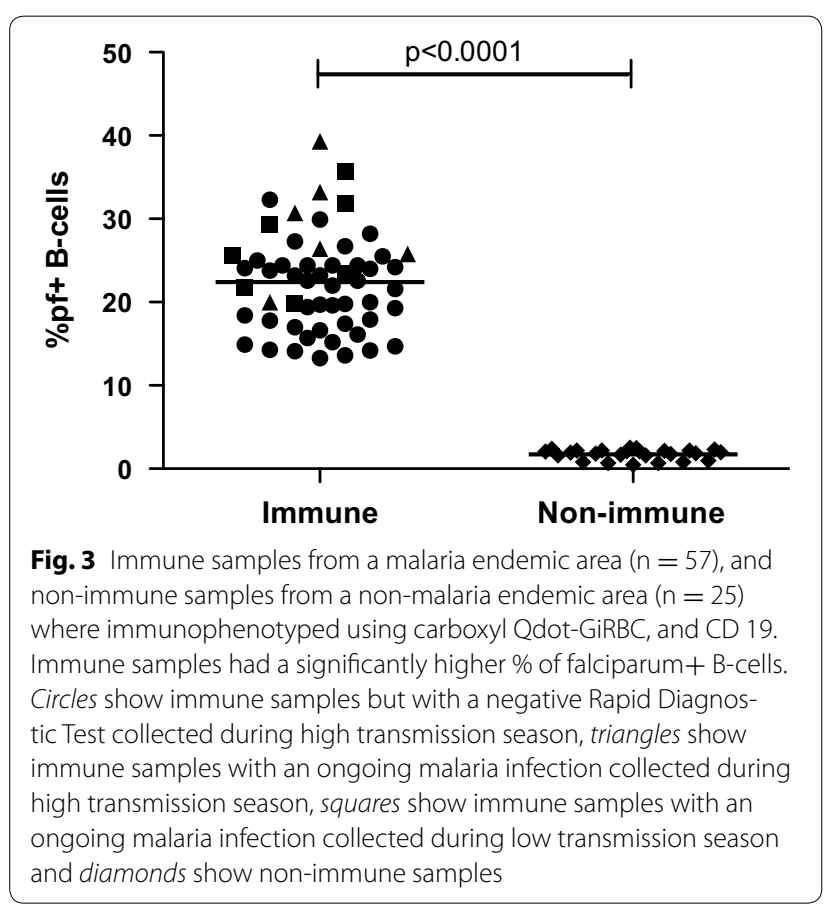

\section{Discussion}

Quantum dot nano crystals and bioconjugates are ideal for use in flow cytometry, and in this study a novel

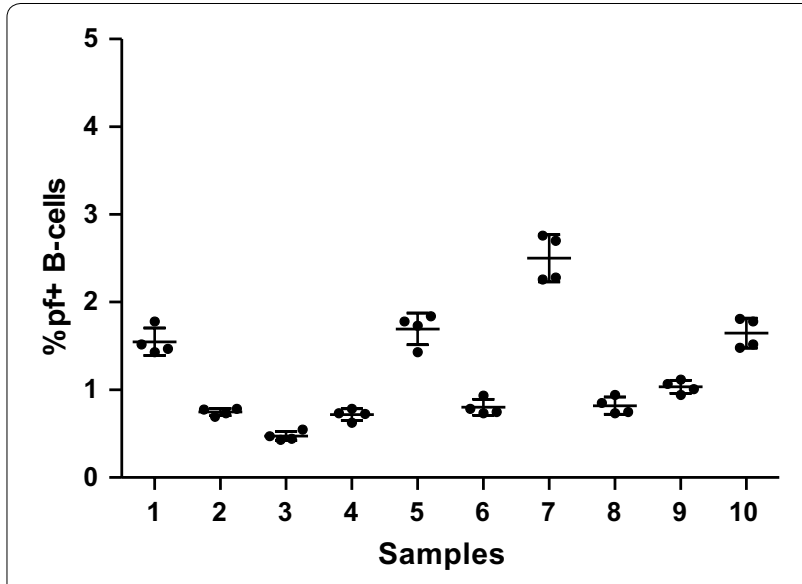

Fig. 4 Samples 1-10 from malaria non-endemic area were immunophenotyped four times to test for reproducibility of the assay. Each sample was run 4 times, lines indicate mean \pm standard deviation

technique for separating $P$. falciparum specific B-cells from other B-cells in humans has been developed. Different Qdots, and different concentration combinations were tested and found carboxylated Qdots to be the best ones in combination with GiRBC. The removal of haemoglobin from the iRBC to form GiRBC was a major improvement in removing unspecific binding. It was not possible to completely remove unspecific binding, but 


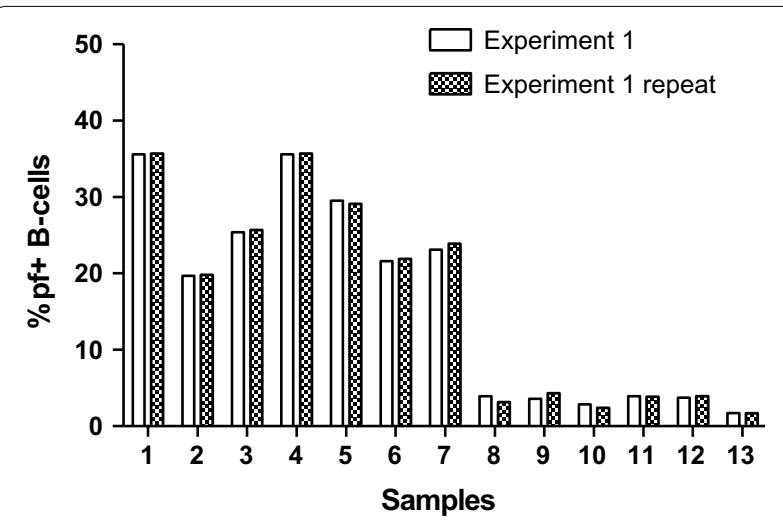

Fig. 5 Samples 1-13 were used twice each in repeat experiments to further test for reproducibility of the assay. Samples 1-7 had on going malaria infection, 8-12 had inflammatory conditions other than malaria and 13 was from a non-endemic area for comparison. 1-12 were collected during low transmission season the differences between immune and non-immune individuals were so large that an estimation of the percentage of P. falciparum specific B-cells in peripheral blood can be made. In the individuals with ongoing infection with P. falciparum, the levels of B-cells were even higher, indicating that the measure is really a specific response. It is also interesting to note that the higher the levels of parasites in the blood, the higher the levels of falciparum+ B-cells. However, the number of samples with parasites in the blood was quite small, and it needs further studies before any firm conclusions about this can be made. All samples were from adults, and since the "immune" individuals live in Uganda where malaria occurs all year around, they have probably had malaria many times before and they can boost a specific response relatively quickly. It is interesting to note that the samples collected from patients with other inflammatory conditions than malaria (5 individuals) in the low transmission season all showed lower values compared to many of the samples collected earlier in the study during high transmission season. Perhaps other B-cells than falciparum+ B-cells are boosted, making the relative numbers of falciparum+ B-cells lower. For those that had an ongoing infection with P. falciparum malaria, the levels of falciparum+ $B$-cells were in the same range whether collected during the high-or low transmission season (Fig. 6), indicating that an acute infection really boosts falciparum+ B-cells. In future studies, investigations on newborns and small children can be considered to further try and understand the development of $P$. falciparum specific B-cells early in life.

It has for long been a matter of debate, to which extent long-term immunity against different antigens can be boosted when the individual is exposed to other

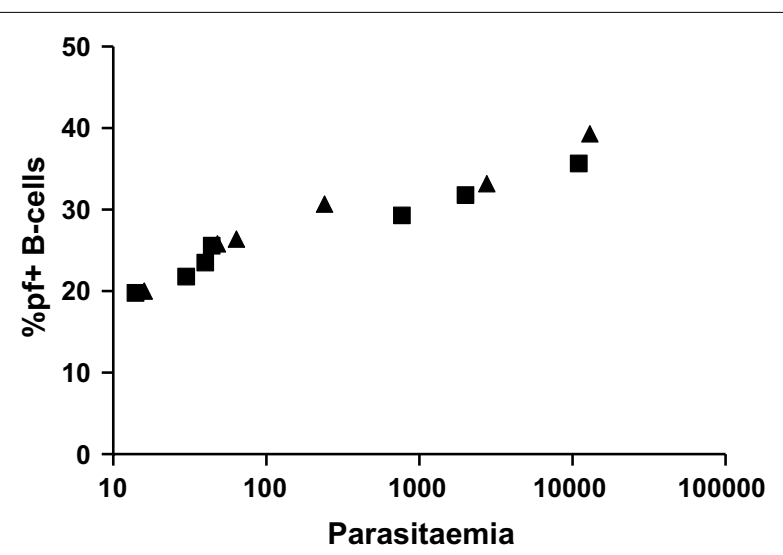

Fig. 6 Parasitaemia compared to \% falciparum+ B-cells, for samples from immune individuals who had $P$. falciparum parasites in the blood. Triangles show samples collected during high transmission season, squares show samples collected during low transmission season

immunostimulatory factors. For malaria, it is quite clear that repeated exposure is necessary to reach a high level of immunity, but it is not yet understood in detail why it takes so long to reach this immunity. Before it has been difficult to study malaria specific B-cells, but if the presently described method is used, it should be easier in future to evaluate specific responses, both in naturally acquired immunity and in vaccine studies. The study capitalized on schizont extract in order to measure all kinds of responses, both against merozoites and iRBC surface molecules. The advantage of this is that high enough levels of B-cells can be found. If B-cells directed only against one specific (recombinant) antigen is looked for, the number of B-cells will probably be too low to be found. However, a combination of antigens might be a way forward in vaccine studies, where specific responses are investigated.

In earlier studies, Elispot assays have been used to try and estimate numbers of $P$. falciparum-specific B-cells. In Elispot, the cells have to survive the experimental environment with activation of the B-cells and transformation into antibody producing cells, and it is difficult to know whether all cells actually persist during this treatment. Several earlier studies have shown conflicting results concerning the correlation between antigen specific IgG levels and memory B-cell frequencies, when Elispot has been used [30, 39, 40]. This indicates that there might be difficulties in the methods that have been used before. It has also been shown that presence of malaria specific B-cells measured by Elispot does not predict protection from a challenge infection [31]. With this new method, no activation of the cells is needed, and because it is based on flow cytometry staining, 
antigen-specific memory B-cells can directly be detected by virtue of their affinity/avidity for cognate antigen which makes it advantageous.

Despite flow cytometry having high-throughput capabilities, it can be hampered by non specific binding of some antigens especially repetitive or complex multi-protein antigens [41]. Future studies will look into sorting of the positive cells and expression of their antibodies to determine the extent to which they are $P$. falciparum-specific.

\section{Conclusion}

This study has shown that there is a major difference in the percentage of $P$. falciparum-specific B-cells in immune compared to non-immune individuals, with the highest levels in those that have parasites in the blood. Using a new method that opens up new possibilities for evaluating $P$. falciparum-specific B-cells, knowledge about how they are sustained in vivo should be facilitated. This method can hopefully be used in both vaccine studies that are based on infected RBCs or individual antigens that can be conjugated to the carboxyl Qdots, and also for studies of development of naturally acquired immunity.

\section{Abbreviations}

Qdots: quantum dots; PBMC: peripheral blood mononuclear cells; iRBCs: Plasmodium falciparum infected red blood cells; GiRBCs: ghost Plasmodium falciparum infected red blood cells; falciparum + B-cells: percentage of CD19+ cells that are positive for $P$. falciparum; falciparum-B-cells: percentage of CD19+ cells that are negative for P. falciparum; GiRBC-Qdot: ghost Plasmodium falciparum infected red blood cells carboxyl quantum dot conjugate.

\section{Authors' contributions}

Conceived the idea and designed the experiments: AL, SR, CR, MW, FK and KP. Sample collection and Laboratory analysis: AL, SR, CR, and KP. Data analysis: AL, $\mathrm{SR}, \mathrm{CR}, \mathrm{MW}, \mathrm{FK}$ and KP. FK, MW and KP contributed the reagents and materials. Wrote the paper: AL, SR, CR, MW, FK and KP. All authors read and approved the final manuscript.

\section{Author details \\ ${ }^{1}$ School of Biomedical Sciences, College of Health Sciences, Makerere Univer- sity, Kampala, Uganda. ${ }^{2}$ Habib Medical School, Islamic University in Uganda, Kampala, Uganda. ${ }^{3}$ Microbiology, Tumor, and Cell Biology, Karolinska Insti- tutet, Solna, Sweden. ${ }^{4}$ Department of Laboratory Medicine, Lund University, Lund, Sweden.}

\section{Acknowledgements}

This work was supported by MSB and a Makerere University/Karolinska Institutet Sida sponsored collaboration Grant. We are grateful to the donors of blood.

\section{Compliance with ethical guidelines}

\section{Competing interests}

The authors declare that they have no competing interests.

Received: 3 June 2015 Accepted: 15 September 2015

Published online: 26 September 2015

\section{References}

1. Struik SS, Riley EM. Does malaria suffer from lack of memory? Immunol Rev. 2004;201:268-90.

2. Cohen S, Mc Gl, Carrington S. Gamma-globulin and acquired immunity to human malaria. Nature. 1961;192:733-7.

3. Lanzavecchia A, Bernasconi N, Traggiai E, Ruprecht CR, Corti D, Sallusto F. Understanding and making use of human memory B cells. Immunol Rev. 2006;211:303-9.

4. Akpogheneta OJ, Duah NO, Tetteh KK, Dunyo S, Lanar DE, Pinder M, et al. Duration of naturally acquired antibody responses to blood-stage Plasmodium falciparum is age dependent and antigen specific. Infect Immun. 2008;76:1748-55.

5. Cavanagh DR, Dodoo D, Hviid L, Kurtzhals JA, Theander TG, Akanmori $\mathrm{BD}$, et al. Antibodies to the $\mathrm{N}$-terminal block 2 of Plasmodium falciparum merozoite surface protein 1 are associated with protection against clinical malaria. Infect Immun. 2004;72:6492-502.

6. Conway DJ, Cavanagh DR, Tanabe K, Roper C, Mikes ZS, Sakihama N, et al. A principal target of human immunity to malaria identified by molecular population genetic and immunological analyses. Nat Med. 2000;6:689-92.

7. Metzger WG, Okenu DM, Cavanagh DR, Robinson JV, Bojang KA, Weiss $\mathrm{HA}$, et al. Serum lgG3 to the Plasmodium falciparum merozoite surface protein 2 is strongly associated with a reduced prospective risk of malaria. Parasite Immunol. 2003;25:307-12.

8. Osier FH, Fegan G, Polley SD, Murungi L, Verra F, Tetteh KK, et al. Breadth and magnitude of antibody responses to multiple Plasmodium falciparum merozoite antigens are associated with protection from clinical malaria. Infect Immun. 2008;76:2240-8.

9. Kinyanjui SM, Conway DJ, Lanar DE, Marsh K. IgG antibody responses to Plasmodium falciparum merozoite antigens in Kenyan children have a short half-life. Malar J. 2007;6:82

10. Ochsenbein AF, Pinschewer DD, Sierro S, Horvath E, Hengartner H, Zinkernagel RM. Protective long-term antibody memory by antigen-driven and Thelp-dependent differentiation of long-lived memory B cells to shortlived plasma cells independent of secondary lymphoid organs. Proc Natl Acad Sci USA. 2000;97:13263-8.

11. Slifka MK, Ahmed R. Long-lived plasma cells: a mechanism for maintaining persistent antibody production. Curr Opin Immunol. 1998;10:252-8.

12. Asito AS, Moormann AM, Kiprotich C, Ng'ang'a ZW, Ploutz-Snyder R, Rochford R. Alterations on peripheral B cell subsets following an acute uncomplicated clinical malaria infection in children. Malar J. 2008;7:238.

13. Langhorne J, Ndungu FM, Sponaas AM, Marsh K. Immunity to malaria: more questions than answers. Nat Immunol. 2008;9:725-32.

14. Bernasconi NL, Traggiai E, Lanzavecchia A. Maintenance of serological memory by polyclonal activation of human memory B cells. Science. 2002;298:2199-202.

15. Sabchareon A, Burnouf T, Ouattara D, Attanath P, Bouharoun-Tayoun $\mathrm{H}$, Chantavanich $\mathrm{P}$, et al. Parasitologic and clinical human response to immunoglobulin administration in falciparum malaria. Am J Trop Med Hyg. 1991;45:297-308.

16. Deloron $\mathrm{P}$, Chougnet C. Is immunity to malaria really short-lived? Parasitol Today. 1992:8:375-8.

17. Marsh K. Malaria — a neglected disease? Parasitology. 1992;104(Suppl):S53-69.

18. Snow RW, Marsh K. The consequences of reducing transmission of Plasmodium falciparum in Africa. Adv Parasitol. 2002;52:235-64.

19. Riley E, Greenwood B. Measuring cellular immune responses to malaria antigens in endemic populations: epidemiological, parasitological and physiological factors which influence in vitro assays. Immunol Lett. 1990;25:221-9.

20. Weiss GE, Crompton PD, Li S, Walsh LA, Moir S, Traore B, et al. Atypical memory $B$ cells are greatly expanded in individuals living in a malariaendemic area. J Immunol. 2009;183:2176-82.

21. Portugal S, Tipton CM, Sohn H, Kone Y, Wang J, Li S, Skinner J, Virtaneva K, Sturdevant DE, Porcella SF, et al. Malaria-associated atypical memory $B$ cells exhibit markedly reduced $B$ cell receptor signaling and effector function. Elife. 2015;4. doi:10.7554/eLife.07218.

22. Stephens R, Albano FR, Quin S, Pascal BJ, Harrison V, Stockinger B, et al. Malaria-specific transgenic CD4(+) T cells protect immunodeficient mice from lethal infection and demonstrate requirement for a 
protective threshold of antibody production for parasite clearance. Blood. 2005;106:1676-84.

23. D'Imperio Lima MR, Alvarez JM, Furtado GC, Kipnis TL, Coutinho A, Minoprio P. Ig-isotype patterns of primary and secondary B cell responses to Plasmodium chabaudi chabaudi correlate with IFN-gamma and IL-4 cytokine production with CD45RB expression by CD4+ spleen cells. Scand J Immunol. 1996;43:263-70.

24. Wykes MN, Zhou YH, Liu XQ, Good MF. Plasmodium yoelii can ablate vaccine-induced long-term protection in mice. J Immunol. 2005;175:2510-6.

25. Carvalho LJ, Ferreira-da-Cruz MF, Daniel-Ribeiro CT, Pelajo-Machado M, Lenzi HL. Germinal center architecture disturbance during Plasmodium berghei ANKA infection in CBA mice. Malar J. 2007;6:59.

26. Udhayakumar V, Kariuki S, Kolczack M, Girma M, Roberts JM, Oloo AJ, et al. Longitudinal study of natural immune responses to the Plasmodium falciparum apical membrane antigen (AMA-1) in a holoendemic region of malaria in western Kenya: Asembo Bay Cohort Project VIII. Am J Trop Med Hyg. 2001;65:100-7.

27. Taylor RR, Egan A, McGuinness D, Jepson A, Adair R, Drakeley C, et al. Selective recognition of malaria antigens by human serum antibodies is not genetically determined but demonstrates some features of clonal imprinting. Int Immunol. 1996;8:905-15.

28. Drakeley CJ, Corran PH, Coleman PG, Tongren JE, McDonald SL, Carneiro I, et al. Estimating medium- and long-term trends in malaria transmission by using serological markers of malaria exposure. Proc Natl Acad Sci USA. 2005;102:5108-13.

29. Cavanagh DR, Elhassan IM, Roper C, Robinson VJ, Giha H, Holder AA, et al. A longitudinal study of type-specific antibody responses to Plasmodium falciparum merozoite surface protein-1 in an area of unstable malaria in Sudan. J Immunol. 1998;161:347-59.

30. Dorfman JR, Bejon P, Ndungu FM, Langhorne J, Kortok MM, Lowe BS, et al. B cell memory to 3 Plasmodium falciparum blood-stage antigens in a malaria-endemic area. J Infect Dis. 2005;191:1623-30.

31. NahrendorfW, Scholzen A, Bijker EM, Teirlinck AC, Bastiaens GJ, Schats $R$, et al. Memory B-cell and antibody responses induced by Plasmodium falciparum sporozoite immunization. J Infect Dis. 2014;210:1981-90.
32. Wipasa J, Suphavilai C, Okell LC, Cook J, Corran PH, Thaikla K, et al. Longlived antibody and $B$ Cell memory responses to the human malaria parasites, Plasmodium falciparum and Plasmodium vivax. PLoS Pathog. 2010;6:e1000770

33. Amanna IJ, Slifka MK. Quantitation of rare memory B cell populations by two independent and complementary approaches. J Immunol Methods. 2006;317:175-85.

34. Riedhammer C, Halbritter D, Weissert R. Peripheral blood mononuclear cells: isolation, freezing, thawing, and culture. Methods Mol Biol. 2014;1304:53-61

35. Beeson JG, Brown GV, Molyneux ME, Mhango C, Dzinjalamala F, Rogerson SJ. Plasmodium falciparum isolates from infected pregnant women and children are associated with distinct adhesive and antigenic properties. J Infect Dis. 1999;180:464-72.

36. Moll K, Kaneko A, Scherf A, Wahlgren M. Methods in malaria research. 6th ed. USA: MR4/ATCC; 2013

37. Bharti PK, Silawat N, Singh PP, Singh MP, Shukla M, Chand G, et al. The usefulness of a new rapid diagnostic test, the First Response Malaria Combo (pLDH/HRP2) card test, for malaria diagnosis in the forested belt of central India. Malar J. 2008:7:126.

38. Ash LR, Orihel TC, Bosman A, Renganathan E, Rio F. Bench, aids for the diagnosis of malaria infections. Geneva: World Health Organization; 2000. p. 24.

39. Fievet N, Chougnet C, Dubois B, Deloron P. Quantification of antibodysecreting lymphocytes that react with Pf155/RESA from Plasmodium falciparum: an ELISPOT assay for field studies. Clin Exp Immunol. 1993;91:63-7.

40. Migot F, Chougnet C, Henzel D, Dubois B, Jambou R, Fievet N, et al. Anti-malaria antibody-producing B cell frequencies in adults after a Plasmodium falciparum outbreak in Madagascar. Clin Exp Immunol. 1995:102:529-34

41. Doucett VP, Gerhard W, Owler K, Curry D, Brown L, Baumgarth N. Enumeration and characterization of virus-specific $B$ cells by multicolor flow cytometry. J Immunol Methods. 2005;303:40-52.

\section{Submit your next manuscript to BioMed Central and take full advantage of:}

- Convenient online submission

- Thorough peer review

- No space constraints or color figure charges

- Immediate publication on acceptance

- Inclusion in PubMed, CAS, Scopus and Google Scholar

- Research which is freely available for redistribution

Submit your manuscript at 